\title{
A daf-7-related TGF- $\beta$ ligand (Hc-tgh-2) shows important regulations on the development of Haemonchus contortus
}

Li He, Hui Liu, Bi-Ying Zhang, Fang-Fang Li, Wen-Da Di, Chun-Qun Wang, Cai-Xian Zhou, Lu Liu, Ting-Ting Li, Ting Zhang, Rui Fang and Min Hu* (D)

\begin{abstract}
Background: In most multicellular organisms, the transforming growth factor- $\beta$ (TGF- $\beta$ ) signalling pathway is involved in regulating the growth and stem cell differentiation. Previous studies have demonstrated the importance of three key molecules in this pathway in the parasitic nematode Haemonchus contortus, including one TGF- $\beta$ type I receptor (Hc-tgfbr1), one TGF- $\beta$ type II receptor (Hc-tgfbr2), and one co-Smad (Hc-daf-3), which regulated the developmental transition from the free-living to the parasitic stages of this parasite. However, almost nothing is known about the function of the TGF- $\beta$ ligand ( $H c$-tgh-2) of H. contortus.
\end{abstract}

Methods: Here, the temporal transcription profiles of Hc-tgh-2 at eight different developmental stages and spatial expression patterns of $\mathrm{Hc}-\mathrm{TGH}-2$ in adult female and male worms of $\mathrm{H}$. contortus have been examined by real-time PCR and immunohistochemistry, respectively. In addition, RNA interference (RNAi) by soaking was employed to assess the importance of Hc-tgh-2 in the development from exsheathed third-stage larvae (XL3s) to fourth-stage larvae (L4s) in H. contortus.

Results: Hc-tgh-2 was continuously transcribed in all eight developmental stages of $\mathrm{H}$. contortus studied with the highest level in the infective third-stage larvae (iL3) and $\mathrm{HC}-\mathrm{TGH}-2$ was located in the muscle of the body wall, intestine, ovary of adult females and testes of adult males. Silencing Hc-tgh-2 by the specific double-stranded RNA (dsRNA), decreased the transcript level of Hc-tgh-2 and resulted in fewer XL3s developing to L4s in vitro.

Conclusions: These results suggested that the TGF- $\beta$ ligand, $\mathrm{HC}-\mathrm{TGH}-2$, could play important roles in the developmental transition from the free-living (L3s) to the parasitic stage (L4s). Furthermore, it may also take part in the processes such as digestion, absorption, host immune response and reproductive development in $\mathrm{H}$. contortus adults.

Keywords: Haemonchus contortus, Transforming growth factor $\beta$ ligand, Development, Reproduction

*Correspondence: mhu@mail.hzau.edu.cn

State Key Laboratory of Agricultural Microbiology, Key Laboratory for the Development of Veterinary Products, Ministry of Agriculture, College of Veterinary Medicine, Huazhong Agricultural University, Wuhan 430070, Hubei, China

\section{Background}

The transforming growth factor- $\beta$ (TGF- $\beta$ ) family, consisting of more than 45 proteins with similar homo- or hetero-dimers containing a cysteine knot structural motif [1], are widely distributed in most metazoans and participate in a variety of biological processes such as development, neurological disorders and immunoregulation [2-4]. According to the structural motifs, members of

(C) The Author(s) 2020. This article is licensed under a Creative Commons Attribution 4.0 International License, which permits use, sharing, adaptation, distribution and reproduction in any medium or format, as long as you give appropriate credit to the original author(s) and the source, provide a link to the Creative Commons licence, and indicate if changes were made. The images or other third party material in this article are included in the article's Creative Commons licence, unless indicated otherwise in a credit line to the material. If material is not included in the article's Creative Commons licence and your intended use is not permitted by statutory regulation or exceeds the permitted use, you will need to obtain permission directly from the copyright holder. To view a copy of this licence, visit http://creativeco mmons.org/licenses/by/4.0/. The Creative Commons Public Domain Dedication waiver (http://creativecommons.org/publicdomain/ zero/1.0/) applies to the data made available in this article, unless otherwise stated in a credit line to the data. 
the TGF- $\beta$ family are divided into five groups including TGF $\beta$ s, activins/inhibin, growth and differentiation factors (GDFs), bone morphogenetic proteins (BMPs) and mullerian inhibitory factor (MIF) $[2,5]$. Different TGF- $\beta$ members have highly specific or even opposite functions, but overlapping functions are still present among them $[2,5]$. Each TGF- $\beta$ protein can act as a specific ligand and bind the specific heterotetrameric receptor consisting of two TGF- $\beta$ type I receptor and two TGF- $\beta$ type II receptor subunits [5], therefore, different TGF- $\beta$ members play diverse roles in the biological processes of multicellular animals due to specific signalling transduction.

In the free-living nematode Caenorhabditis elegans, there are five TGF- $\beta$ ligands ( $\mathrm{Ce}$-DBL-1, $\mathrm{Ce}$-DAF-7, $\mathrm{Ce}$ UNC-129, Ce-TIG-2 and Ce-TIG-3) involved in regulating essential development including dauer formation, body-size determination and male tail morphology $[6$, 7]. However, so far, only two complete TGF- $\beta$ signalling pathways (DBL-1 pathway and DAF-7 pathway) have been elucidated in detail $[7,8]$. The signal transmitting from $\mathrm{Ce}$-DBL-1 is mainly associated with body size regulation and male tail development $[9,10]$, in addition, it also regulates the innate immunity and lifespan [11-13]. In contrast, $\mathrm{Ce}$-DAF-7 is expressed in ASI neurons and regulates the dauer/continuous developmental switch $[14,15]$. Besides, $\mathrm{Ce}$-DAF-7 is also involved in the regulation of longevity, reproduction and fat metabolism [16-18].

Compared with $C$. elegans, much less is known about the TGF- $\beta$ ligands in parasitic nematodes. TGF- $\beta$ ligand homologues were identified from a number of parasitic nematodes and limited functional studies were carried out. For example, in the filarial nematodes Brugia malayi and $B$. pahangi, two TGF- $\beta$ homolog-1 genes (Bm-tgh- 1 and $B p$-tgh-1, respectively) were described as members of the TGF- $\beta$ family, revealing that these genes were more similar to the DBL- 1 subfamily members and may play a role in the molting process in parasites inside the mammalian host [19]. Following this work, a homologue of C. elegans daf- 7 was then identified in B. malayi (named as Bm-tgh-2) [20], which was detectable over the lifecycle of this filarial parasite with the highest transcription in the microfilarial stage [20]. Subsequently, in the dog hookworm Ancylostoma caninum, two TGF- $\beta$ ligand genes (Ac-dbl-1 and $A c-d a f-7)$ were identified and found that they were involved in regulating the male tail pattern and developmental arrest, respectively [21, 22]. Meanwhile, three homologues of $\mathrm{Ce}$-daf-7 were cloned from human and canine parasitic nematode Strongyloides stercoralis (Ss-tgh-1) and its two close relatives Strongyloides ratti (Sr-daf-7) and Parastrongyloides trichosuri (Pt-daf-7) and were all detected with the highest transcription in the infective third-stage larvae (iL3) [23, 24].
Regarding these three genes, Ss-tgh-1 was then verified exclusively transcribed in the iL3 stage by RNAseq, suggesting that Ss-tgh-1 could regulate the iL3 arrest [25]. In addition, the functional conservation of Pt-daf-7 compared with $\mathrm{Ce}$-daf-7 was further assessed by heterologous gene rescue using a C. elegans mutant, revealing that Pt-daf-7 could not rescue the Ce-daf-7 (e1372) mutant strain although Pt-daf-7 could be expressed in the ASI of C. elegans [26].

Recently, TGF- $\beta$ ligand homologues were also identified from four trichostrongyloid nematodes (Heligmosomoides polygyrus, Nippostrongylus brasiliensis, Teladorsagia circumcincta and Haemonchus contortus). Nevertheless, functional studies have not been conducted in these nematodes except for detection of the transcript levels of these genes in their corresponding parasites [27]. More recently, in $H$. contortus, three molecules of the TGF- $\beta$ signalling pathway, including one TGF- $\beta$ type I receptor $(H c-t g f b r 1)$, one TGF- $\beta$ type II receptor $(H c$ tgfbr2) and one co-Smad (Hc-daf-3), were identified to be involved in regulating the developmental transition from the free-living L3 to the parasitic stage [28-30]. In the present study, we extended the previous work and explored the functions of the TGF- $\beta$ ligand homologue of $H$. contortus (Hc-tgh-2), aiming at illuminating its role in the regulation of the developmental processes through the TGF- $\beta$ signalling pathway in $H$. contortus.

\section{Methods \\ Haemonchus contortus strain and its maintenance}

The $H$. contortus Haecon-5 strain was maintained in goats (3-6 months-old, helminth-free), which were infected orally with $8000-10,000$ iL3s. Eggs were isolated from the faeces of infected goats, and first-stage and second-stage larvae (L1s and L2s) as well as iL3s produced by a co-culture method [31]. Fourth-stage larvae (L4s) and adults of $H$. contortus were collected from the abomasa of infected goats, euthanized with an overdose of pentobarbitone sodium (Lethobarb; Virbac Pty Ltd, Peakhurst, New South Wales, Australia) at 8 or 30 days post-infection, respectively, then all L4s and adults were extensively washed in physiological saline, and female and male worms separated prior to snap-freezing in liquid nitrogen and then stored at $-80^{\circ} \mathrm{C}$ until use.

\section{Phylogenetic analyses of amino acid sequence data}

The amino acid sequences of $\mathrm{Hc}$-TGH-2 (GenBank: ACQ84508.1) and the homologues from 17 species (Ancylostoma caninum, Ascaris suum, Brugia malayi, Caenorhabditis briggsae, Caenorhabditis elegans, Capra hircus, Danio rerio, Heligmosomoides polygyrus, Homo sapiens, Mus musculus, Nippostrongylus brasiliensis, Parastrongyloides trichosuri, Strongyloides stercoralis, 
Strongyloides ratti, Teladorsagia circumcincta, Toxocara canis and Trichinella spiralis; Table 1) were aligned. Phylogenetic analyses of the aligned sequence data were conducted using the neighbor-joining (NJ), maximum parsimony (MP) and maximum likelihood (ML) methods employing the Jones-Taylor-Thornton (JTT) model [32]. Confidence limits were assessed using a bootstrap procedure employing 1000 pseudoreplicates for NJ, MP and ML in MEGA v.6.0 [32]. A 50\% cut-off value was implemented for the consensus tree. A TGF- $\beta$ type II receptor from C. elegans (GenBank: CCD63118.1) was used as the outgroup for phylogenetic analyses.

\section{Transcriptional analyses by real-time PCR}

Total RNA was isolated from individual developmental stages of $H$. contortus (eggs, L1, L2, iL3, male and female L4s, and male and female adults) using TRIzol (Life Technologies, Shanghai, China). RNA integrity and yields were verified by electrophoresis and spectrophotometric analysis (NanoDrop Technologies, Beijing, China). Complementary DNA (cDNA) was synthesized from RNA $(1 \mu \mathrm{g})$ employing the PrimeScript ${ }^{\mathrm{TM}} \mathrm{RT}$ reagent kit with gDNA Eraser (Perfect Real Time; Takara, Beijing, China). Nucleic acids were stored at $-80^{\circ} \mathrm{C}$ until use.

According to the identified coding sequence of $\mathrm{Hc}$ tgh-2 [27] (GenBank: FJ391183), one set of primers (Hctgh-2-rtF/R; Additional file 1: Table S1) were designed to detect the transcriptional level of Hc-tgh-2 in eight developmental stages of $H$. contortus by real-time PCR under the protocol as follows: $95{ }^{\circ} \mathrm{C}$ for $30 \mathrm{~s}$; followed by 40 cycles at $95{ }^{\circ} \mathrm{C}$ for $15 \mathrm{~s}, 60^{\circ} \mathrm{C}$ for $15 \mathrm{~s}$ and $72{ }^{\circ} \mathrm{C}$ for $20 \mathrm{~s}$. A $\beta$-tubulin 8-9 gene (Hc-tub8-9) was set as a reference in all samples (in triplicate) [43] employing a set of specific primers Hc-tub8-9-rtF/R (Additional file 1: Table S1). The data of the real-time PCR were analyzed by comparing with the relative quantities of egg $(\mathrm{egg}=1)$ using the $2^{-\triangle \Delta \mathrm{Cq}}$ method [44]. A one-way ANOVA was used in the statistical analysis and each $P$-value was determined by post-hoc pairwise comparisons. This assay was repeated three times.

\section{Prokaryotic expression of $\mathrm{Hc}-\mathrm{TGH}-2$ and the localization of $\mathrm{Hc}-\mathrm{TGH}-2$ in $\mathrm{H}$. contortus}

According to the analysis on antigen epitopes of $\mathrm{Hc}$ TGH-2 by the software DNAstar (http://www.dnast ar.com/), one set of primers (Hc-tgh-2-eF/R) was designed to amplify the partial cDNA (151-732 bp) of Hc-tgh- 2 under the PCR cycling protocol: $95^{\circ} \mathrm{C}$ for 3 min; followed by 35 cycles at $95^{\circ} \mathrm{C}$ for $30 \mathrm{~s}, 60^{\circ} \mathrm{C}$ for $40 \mathrm{~s}$ and $72{ }^{\circ} \mathrm{C}$ for $20 \mathrm{~s}$; and then $72{ }^{\circ} \mathrm{C}$ for $5 \mathrm{~min}$. The amplicon was inserted into the expression vector pET-28a and the construct was transformed into E. coli Rosseta-DE3, then the protein $\mathrm{Hc}$-TGH-2 (51-244 aa) was expressed and purified, followed by SDS-PAGE detection. Purified recombinant $\mathrm{Hc}$-TGH-2 protein $(500 \mu \mathrm{g})$ was injected subcutaneously into two rabbits with multiple sites (4 immunizations with a 2-week interval between each immunization). A pre-bleed was taken from each rabbit prior to the first injection, while a final bleed was taken one week after the last immunization. Serum was treated according to a standard procedure [45]. The serum from the pre-bleed was designated as negative serum while the serum from the final bleed was designated as positive serum. All the sera were analyzed by western blot using the total protein extracted from adults of $H$. contortus with the Total Protein Extraction Kit (Bestbio Company, Guangzhou, China).

The serum was used to detect the expression patterns of $\mathrm{Hc}$-TGH-2 in adult males and females of $H$. contortus by immunohistochemistry, respectively, as previously described [29]. In brief, approximately $50 \mathrm{H}$. contortus adult males or females were fixed in $4 \%$ paraformaldehyde (Biosharp, Hefei, China) at $4{ }^{\circ} \mathrm{C}$, respectively. Then the single worm was dehydrated in a graded ethanol series ( $75 \%$ for $4 \mathrm{~h}, 85 \%$ for $2 \mathrm{~h}, 90 \%$ for $2 \mathrm{~h}, 95 \%$ for $1 \mathrm{~h}$ once and $100 \%$ twice for $30 \mathrm{~min}$ ) sequentially, followed by embedding in paraffin. Sections $(4 \mu \mathrm{m})$ were cut and flattened on polylysine slides, followed by paraffinating (xylene treated twice for $20 \mathrm{~min}$ ) and rehydrating in a series of graded ethanol (100\% twice for $10 \mathrm{~min}$; $95 \%$

Table 1 Sequences used for phylogenetic analyses in the present study

\begin{tabular}{lll}
\hline Species & GenBank ID & Reference \\
\hline Ancylostoma caninum & AAY79430.1 & {$[21]$} \\
Ascaris suum & ADY41407.1 & {$[33]$} \\
Brugia malayi & CDQ03041.1 & {$[34]$} \\
Caenorhabditis briggsae & CAP21409.1 & {$[35]$} \\
Caenorhabditis elegans & CCD61866.1 & {$[14]$} \\
Caenorhabditis elegans & CCD63118.1 & {$[36]$} \\
Capra hircus & XP_017903600.1 & {$[37]$} \\
Danio rerio & AAN03678.2 & {$[38]$} \\
Haemonchus contortus & ACQ84508.1 & {$[27]$} \\
Heligmosomoides polygyrus & ACR27076.1 & {$[27]$} \\
Homo sapiens & NP_005802.1 & {$[39]$} \\
Mus musculus & NP_034402.1 & {$[40]$} \\
Nippostrongylus brasiliensis & ACR27077.1 & {$[27]$} \\
Parastrongyloides trichosuri & ABQ10586.1 & {$[23]$} \\
Strongyloides stercoralis & AAV84743.1 & {$[24]$} \\
Strongyloides ratti & AAT79346.1 & {$[23]$} \\
Teladorsagia circumcincta & ACR27078.1 & {$[27]$} \\
Toxocara canis & KHN71899.1 & {$[41]$} \\
Trichinella spiralis & KRY30333.1 & {$[42]$} \\
\hline Seguce &
\end{tabular}

a Sequence was used as the outgroup for phylogenetic analyses 
once for $5 \mathrm{~min}, 90 \%$ once for $5 \mathrm{~min}, 80 \%$ once for $5 \mathrm{~min}$, $70 \%$ once for $5 \mathrm{~min}$ each), then washed with phosphate buffer solution (PBS) for three times (5 min). Antigens were recovered by the microwave, then endogenous catalase was eliminated by $3 \%$ hydrogen peroxide. The sections were washed with PBS three times (5 min), then blocked with $5 \%$ bovine serum albumin (BSA) for $20 \mathrm{~min}$ in a humidified chamber. The sections were incubated with approximately $50 \mu \mathrm{l}$ polyclonal anti- $\mathrm{Hc}$-TGH-2 antibody (positive serum) or negative serum (each at 1:100 dilution) at $4{ }^{\circ} \mathrm{C}$ overnight, respectively. The serum was removed and the sections were washed three times with PBS $(5 \mathrm{~min})$. Then the sections were incubated at $37^{\circ} \mathrm{C}$ for $50 \mathrm{~min}$ in anti-rabbit immunoglobulin (IgG) (raised in sheep) conjugated with fluorescein (Aspen, Chengdu, China) in the dark. The sections were then washed with PBS for three times $(5 \mathrm{~min})$ to remove the secondary antibody. After that, the sections were incubated at room temperature for $5 \mathrm{~min}$ in 4, 6-diamidino-2-phenylindole (DAPI) solution in the dark. The sections were washed in PBS three times (5 min) again and then assessed in detail using an epifluorescence microscope (Olympus CX-21; Olympus, Shenzhen, China). All images were processed using Adobe Photoshop CS 6.0.

\section{Preparation of double-stranded RNA and RNA interference (RNAi) in $\mathrm{H}$. contortus}

Two sets of specific PCR primers (Hc-tgh-2-sF1/sR1 and Hc-tgh-2-sF2/sR2) were designed to amplify the coding sequences of the $\mathrm{Hc}$-TGH-2 functional domain (864 bp) for constructing two plasmids that were used to synthesize specific dsRNA (Additional file 1: Table S1) as previously described $[28,29]$. One set of primers (Hctgh-2-sF1/sR1) was tagged with the T7 promoter site in forward direction and restriction enzyme BamH I site in reverse direction, respectively. Another set of primers (Hc-tgh-2-sF2/sR2) was tagged with the restriction enzyme $B a m \mathrm{H}$ I site in forward direction and the T7 promoter site in reverse direction, respectively. The sequences of the $\mathrm{Hc}$-TGH-2 functional domain (864 bp) were amplified by these two sets of specific PCR primers under the same cycling conditions: $95^{\circ} \mathrm{C}$ for $5 \mathrm{~min}$; followed by 35 cycles of $95{ }^{\circ} \mathrm{C}$ for $30 \mathrm{~s}, 55.4{ }^{\circ} \mathrm{C}$ for $30 \mathrm{~s}$, $72{ }^{\circ} \mathrm{C}$ for $2 \mathrm{~min}$; and then $72{ }^{\circ} \mathrm{C}$ for $5 \mathrm{~min}$. PCR products were then inserted into pTOPO-Blunt Simple vector (Aidlab Biotechnologies Co., Ltd, Beijing, China) by a ClonExpress ${ }^{\mathrm{TM}}$ II One Step Cloning Kit (Vazyme Biotech Co., Ltd, Nanjing, China), respectively. The irrelevant control was a cry1Ac gene from Bacillus thuringiensis (Bt-cry1Ac, GenBank: GU322939.1), which has no homology with any $H$. contortus gene $[28,29]$. The sequence of $B t$-cry1Ac was cloned using two sets of specific PCR primers Bt-cry1Ac-sF1/sR1 and Bt-cry1Ac-sF2/
sR2 (Additional file 1: Table S1) under the following cycling protocol: $95^{\circ} \mathrm{C}$ for $5 \mathrm{~min}$; followed by 35 cycles of $95{ }^{\circ} \mathrm{C}$ for $30 \mathrm{~s}, 55{ }^{\circ} \mathrm{C}$ for $30 \mathrm{~s}, 72{ }^{\circ} \mathrm{C}$ for $1 \mathrm{~min}$; then $72{ }^{\circ} \mathrm{C}$ for $5 \mathrm{~min}$. PCR products were then inserted into pTOPO-Blunt Simple vector, as previously described. All constructs were extracted using plasmid Maxi Kit (Aidlab Biotechnologies Co., Ltd) and then were estimated spectrophotometrically (NanoDrop Technologies) and stored at $-20{ }^{\circ} \mathrm{C}$ until use, respectively. The restriction enzyme $B a m H I$ was used to linearize the constructs containing Hc-tgh-2 or Bt-cry1Ac fragments, respectively, and the linearized templates were verified by electrophoresis and spectrophotometric analysis (NanoDrop Technologies) and used to synthesize single-stranded RNA (ssRNA) using a RNA large-scale T7 production system according to the instruction manual of MEGAscript ${ }^{\circledR}$ T7 Transcription Kit (Ambion, Shanghai, China). An equal quantity $(\sim 500 \mu \mathrm{g})$ of sense ssRNA and antisense ssRNA were used to synthesize dsRNA with the treatment of $5 \times$ annealing buffer at room temperature for $2 \mathrm{~h}$. The quality and yield of ssRNA and dsRNA were verified by electrophoresis and spectrophotometric analysis (NanoDrop Technologies), respectively. All RNA was immediately frozen and stored at $-80^{\circ} \mathrm{C}$ until use.

The RNA interference assay was performed as previously described [28]. Briefly, $H$. contortus L3s collected from faecal culture were exsheathed in $0.1 \%$ sodium hypochlorite/PBS for $30 \mathrm{~min}$ at $38^{\circ} \mathrm{C}$, followed by washing twice in sterile PBS by centrifugation at $600 \times g$ ( $5 \mathrm{~min}$ ) at $23^{\circ} \mathrm{C}$ and four times in PBS containing antibiotic-antimycotic solution (Gibco, Shanghai, China). Then, the exsheathed L3s (xL3s) were suspended in Earle's Balanced Salt Solution (EBSS, pH adjusted to 5.2; SigmaAldrich, Shanghai, China) with antibiotic-antimycotic solution (Gibco) with a final concentration at 33,000 xL3/ $\mathrm{ml}$ and incubated with different dsRNA $(1 \mathrm{mg} / \mathrm{ml})$. Before incubation, the Hc-tgh-2 dsRNA, Bt-cry1Ac-specific dsRNA (irrelevant control) or nuclease-free water (blank control) were pre-incubated (separately) with RNasin (8 $\mathrm{U})$ and Lipofectin Reagent (Invitrogen, Shanghai, China) for $10 \mathrm{~min}$ at $25^{\circ} \mathrm{C}$ (room temperature), respectively, and added into $30 \mu \mathrm{l}$ of EBSS cultures containing xL3s. After incubation at $37{ }^{\circ} \mathrm{C}$ in $20 \% \mathrm{CO}_{2}$ for $24 \mathrm{~h}, 300$ larvae were transferred to $100 \mu \mathrm{l}$ of fresh EBSS without dsRNA (in triplicate) and cultured for another 7 days and the replicate cultures were examined by microscopy to count the numbers of xL3s and L4s according to the morphological changes of the buccal capsule $[28,46,47]$. The remaining larvae were collected to isolate RNA for detecting the transcriptional change of the gene $\mathrm{Hc}$-tgh-2 by realtime PCR with one set of primers (Hc-tgh-2-rtF/R; Additional file 1: Table S1). $18 S$ rRNA was used as a reference marker [48] and the sequences of primers Hc-18s-rtF/R 
are shown in Additional file 1: Table S1. The PCR cycling protocol used was: $95{ }^{\circ} \mathrm{C}$ for $30 \mathrm{~s}$, followed by 40 cycles at $95{ }^{\circ} \mathrm{C}$ for $15 \mathrm{~s}, 60^{\circ} \mathrm{C}$ for $15 \mathrm{~s}$ and $72{ }^{\circ} \mathrm{C}$ for $20 \mathrm{~s}$. The efficiency of the PCR was calculated using an established formula and the real-time PCR data was subjected to analysis using the $2^{-\Delta \Delta C q}$ method [44].

\section{Results}

\section{Phylogenetic analyses of amino acid sequence data}

The amino acid sequence of the TGF- $\beta$ ligand homologue of $H$. contortus (designated as $H c$-TGH-2) was obtained from GenBank (accession number ACQ84508.1 [27]). Phylogenetic analyses showed that the topologies of the MP, ML and NJ trees were concordant. $\mathrm{Hc}$-TGH-2 grouped together with homologues from four strongylid parasitic nematodes including Ancylostoma caninum, Heligmosomoides polygyrus, Nippostrongylus brasiliensis and Teladorsagia circumcincta with $100 \%$ nodal support, which formed a cluster (88\%) with DAF-7 homologues of two Caenorhabditis spp. (Fig. 1). This big cluster and another smaller cluster $(100 \%)$ containing three TGF- $\beta$ ligand homologues from two parasites of the Ascaridata (Ascaris suum and Toxocara canis) and one parasite of the Filarioidea (Brugia malayi) grouped together with $82 \%$ nodal support (Fig. 1). One TGF- $\beta$ ligand homologue from Trichinella spiralis formed a cluster (82\%) with four TGF- $\beta$ ligand homologues from four metazoans (Capra hircus, Danio rerio, Homo sapiens and Mus musculus), which grouped together with 10 selected TGF- $\beta$ ligand homologues from strongylid, ascarid and filarial nematodes by $83 \%$ nodal support, to the exclusion of TGF- $\beta$ ligand homologues of three parasitic nematodes (Parastrongyloides trichosuri, Strongyloides stercoralis and Strongyloides ratti) that have an alternative free-living life-cycle (Fig. 1).

\section{Transcriptional analysis of $\mathrm{Hc}$-tgh-2 in eight different developmental stages of $H$. contortus}

The relative transcripts of $\mathrm{Hc}$-tgh-2 were detectable in eight different developmental stages (eggs, L1s, L2s, iL3s, female L4s, male L4s, adult females and adult males) of H. contortus (Fig. 2). The transcript abundance of $\mathrm{Hc}$ tgh-2 was highest at iL3 stage, with significant differences compared with other developmental stages $\left(F_{(7}\right.$, ${ }_{16}=20.11002, P<0.0001$, respectively) (Fig. 2 ). There was no statistically significant difference among all other developmental stages except for iL3 (Fig. 2).

\section{Localization of $\mathrm{Hc}-\mathrm{TGH}-2$ in $\mathrm{H}$. contortus adults}

The coding sequence of truncated Hc-TGH-2 (51-244 aa, $29 \mathrm{KD}$ ) was $582 \mathrm{bp}$ in length and expressed in E. coli Rosseta-DE3 (Additional file 2: Figure S1). The polyclonal antibody against $\mathrm{rHc}$-TGH-2 produced by immunizing rabbits could bind to the native $\mathrm{Hc}$-TGH-2 specifcally (Additional file 3: Figure S2). Using this polyclonal antibody as a probe in the immunobiochemical assay, $\mathrm{Hc}$-TGH-2 was detected in the muscle of the body wall, intestine and ovaries of $H$. contortus adult females (Fig. $3 \mathrm{a}-\mathrm{h}$ ). In adult males, $\mathrm{Hc}$-TGH-2 was expressed in the muscle of the body wall, intestine and testes (Fig. 3i-p).

\section{Effect of silencing $\mathrm{Hc}$-tgh-2 on the development of $H$. contortus $\mathrm{XL} 3$ in vitro}

After xL3 was soaked in Hc-tgh-2 dsRNA for $24 \mathrm{~h}$, the transcriptional level of $\mathrm{Hc}$-tgh-2 was significantly decreased compared with the blank control (no dsRNA) and irrelevant dsRNA control group (Bt-cry1Ac dsRNA) $\left(F_{(2,6)}=25.95825, P=0.0021\right.$ and $P=0.0026$, respectively), and there was no statistically significant difference between the two control groups (Fig. 4a). In addition, silencing $H c$-tgh-2 resulted in fewer xL3s developing to L4s in vitro after incubation for another 7 days compared with any control groups $\left(F_{(2,10)}=13.01698, P=0.0035\right.$ and $P=0.0033$, respectively) (Fig. $4 \mathrm{~b}$ ).

\section{Discussion}

In the present study, extending from our previous work on molecules in the TGF- $\beta$ pathway [28-30], the genetic relationship of a predicted TGF- $\beta$ ligand of $H$. contortus (Hc-TGH-2) with selected homologues from different metazoan species were analysed. In addition, the temporal transcriptional and spatial expression profiles of its coding gene ( $\mathrm{Hc}$-tgh-2) were explored and its importance in controlling the development from xL3s (free-living stage) to L4s (parasitic stage) was also investigated.

Phylogenetic analyses revealed that $\mathrm{Hc}$-TGH-2 was closer to the DAF-7 homologues of two Caenorhabditis spp. than the TGF- $\beta$ ligands from metazoans, which is different from the phylogenetic relationships of TGF- $\beta$ receptors from $H$. contortus (Hc-TGFBR1 and Hc-TGFBR2) being more distant from those of Caenorhabditis spp. and metazoans [28, 29]. It is likely that the molecules of the TGF- $\beta$ signalling pathway from $H$. contortus were divergent along with the evolution of this pathway in parasitic nematodes. It is proposed that the TGF- $\beta$ signalling pathway in parasitic nematodes played a role in maintaining the arrested state $[49,50]$, however, the function of TGF- $\beta$ ligand in different parasitic nematodes may be different due to the divergent conservation of the amino acid sequences, especially for those from $P$. trichosuri, S. stercoralis and S. ratti as they did not group with the TGF- $\beta$ ligands of other selected nematodes.

In the present study, the transcripts of $\mathrm{Hc}$-tgh-2 were detected at eight different developmental stages, the 


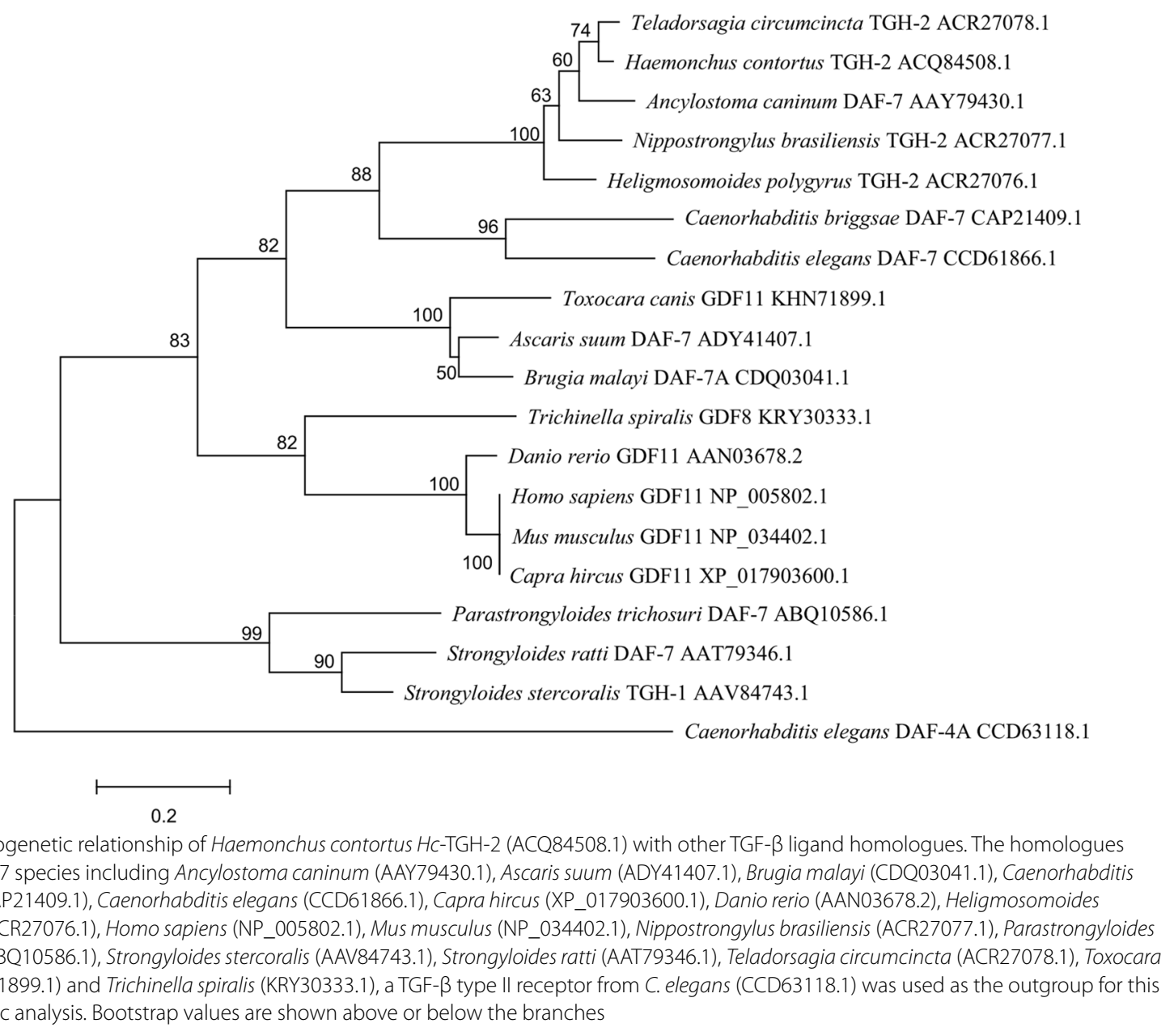

results showed that the transcriptional profiles of $\mathrm{Hc}$ tgh-2 in eggs, iL3s, L4s and adults were consistent with a previous report [27] and the transcriptional profiles of Hc-tgh-2 at other developmental stages (L1s and L2s) were supplemented. In $H$. contortus, the transcripts of $\mathrm{Hc}$-tgh-2 were detected in eggs at a lower level and reached a peak in iL3s (arrested stage), which is similar to the transcriptional profile of TGF- $\beta$ ligands from some parasitic nematodes including $A$. caninum [21, 22], N. brasiliensis [27], P. trichosuri [23], S. stercoralis [24] and S. ratti [23], but different from that of Ce-daf-7 in C. elegans [14]. In C. elegans, the transcript abundance of Ce-daf-7 is highest in the L1 stage (prior to the arrested stage) and lowest in the dauer stage, and it is deemed that the TGF- $\beta$ signalling pathway controls the dauer/reproductive developmental choice in C. elegans [14]. Nevertheless, the arrested stage (iL3s) is inevitable in parasitic nematodes, thus it may not be necessary for parasitic nematodes to regulate the process of entry into the arrested stage. The highest transcript levels of TGF- $\beta$ ligands in iL3s of parasitic nematodes suggested that the TGF- $\beta$ signalling pathway perhaps plays an important role in the steps behind the process of entering into the arrested stage, which means that the TGF- $\beta$ signalling pathway may prefer to maintain the arrested stage and/ or regulate the recovery of development. It has been presumed that the recovery of the development of iL3s is depended on the insulin-like signalling pathway, but not the TGF- $\beta$ signalling pathway [51], thus parasitologists prefer to believe that the role of the TGF- $\beta$ signalling pathway is maintaining the arrested stage $[49,50]$. However, this viewpoint may not be broadly applied as the transcript levels of TGF- $\beta$ ligands in T. circumci$n c t a$ and $H$. polygyrus are not highest in iL3s, but peak in adults and eggs respectively [27]. Furthermore, even in $H$. contortus, the transcription levels of the TGF- $\beta$ type I receptor gene $H c$-tgfbr 1 was highest in adult females [28]. Taken together, we propose that the functions of the TGF- $\beta$ signalling pathway may have arisen some changes 


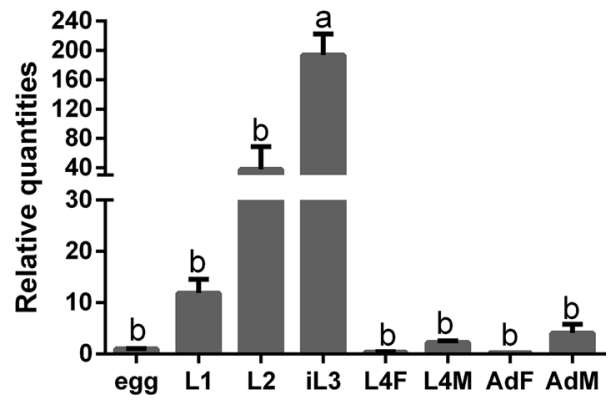

Fig. 2 Transcriptional levels of the $\mathrm{Hc}$-tgh-2 gene in eight developmental stages of Haemonchus contortus. The relative quantities (compared with egg, egg $=1$ ) are shown as mean values ( \pm standard error of the mean, SE). Abbreviations: Egg, eggs; L1, first-stage larvae; L2, second-stage larvae; iL3, infective third-stage larvae; $L 4 F$, females of fourth-stage larvae; $L 4 M$, males of fourth-stage larvae; AdF, adult females; AdM, adult males. The statistical analysis showed that ANOVA, $F_{(7,16)}=20.11002, P<0.0001$. Egg vs $L 1, P=0.9994$; Egg vs $L 2, P=0.6577$; Egg vs iL3, $P<0.0001$; Egg vs $L 4 F, P>0.9999$; Egg vs $L 4 M, P>0.9999 ;$ Egg vs $A d F, P>0.9999$; Egg vs AdM, $P>0.9999 ;$ L1 vs L2, $P=0.9090 ;$ L1 vs iL3, $P<0.0001$; L1 vs $L 4 F, P=0.9991 ; L 1$ vs $L 4 F, P=0.9997 ; L 1$ vs $A d F, P=0.9990 ; L 1$ vs AdM, $P>0.9999 ; \mathrm{L} 2$ vs iL3, $P<0.0001 ; \mathrm{L} 2$ vs $L 4 F, P=0.6399 ; \mathrm{L} 2$ vs $L 4 \mathrm{~F}$, $P=0.6924 ; \mathrm{L} 2$ vs $\mathrm{AdF}, P=0.6358 ; \mathrm{L} 2$ vs $\mathrm{AdM}, P=0.7419 ; \mathrm{iL} 3$ vs $\mathrm{L} 4 \mathrm{~F}$, $P<0.0001 ;$ iL3 vs L4M, $P<0.0001$; iL3 vs AdF, $P<0.0001$; iL3 vs AdM, $P<0.0001$; L4F vs L4M, $P>0.9999 ;$ L4F vs AdF, $P>0.9999 ;$ L4F vs AdM, $P>0.9999 ; L 4 M$ vs AdF, $P>0.9999 ; L 4 M$ vs AdM, $P>0.9999 ; A d F$ vs $\mathrm{AdM}, P>0.9999$. There were significant differences between stages indicated by different capital letters $(a, b)(P<0.01)$

or divergence in the evolution of parasitic nematodes. The mechanisms need to be investigated in the future.

In our opinion, the TGF- $\beta$ signalling pathway may prefer to regulate the recovery of development in the arrested stage (iL3s) in $H$. contortus on account of the decreased proportion of $H$. contortus L4s developed from xL3 with downregulated $H c$-tgh-2 induced by RNAi in vitro, which is similar to the results of other three key molecules of the TGF- $\beta$ signalling pathway in H. contortus studied recently, including a TGF- $\beta$ type I receptor (Hc-tgfbr1) [28], a TGF- $\beta$ type II receptor (Hc-tgfbr2) [29] and a co-Smad (Hc-daf-3) [30]. This is different from the functions of this signaling in A. caninum [51]. Both $H$. contortus and $A$. caninum are Strongylida nematodes of clade $\mathrm{V}$ [52], however, these two parasitic nematodes have different routes to infect the appropriate hosts. A majority (85\%) of $A$. caninum L3s infect the hosts via the percutaneous route and resume feeding within $48 \mathrm{~h}$ postinfection, a minority (15\%) of $A$. caninum L3s can infect hosts orally and most larvae could only resume feeding until they develop to L4s [53]. The resumption of feeding was used as a marker for studying the developmental resumption in $A$. caninum after the parasites enter into the host [51]. However, in H. contortus, L3s can only infect the host via the oral route and are unable to resume feeding until the L3s develop to L4s [54], which means that feeding resumption may not be a good marker for studying the developmental resumption of L3s in $\mathrm{H}$. contortus. Therefore, we propose that the TGF- $\beta$ signalling pathway in different parasitic nematodes (for example, $A$. caninum or $H$. contortus) may function differently in the developmental recovery. This needs to be investigated in the future by in vivo analysis of RNAi treated parasites as previously described [55], which will provide some ideas for controlling $H$. contortus.

In $H$. contortus, the muscles of the body wall act as storage for glycogen, phospholipids and neutral lipids [56], thus the Hc-tgh-2 may be involved in storage for glycogen, phospholipids and neutral lipids due to its expression in the muscle cells of the body wall in adult worms. The body wall is the first line of $H$. contortus to be contacted by the host environment, thus, it is likely that $H c$-tgh-2 may be related to the survival of $H$. contortus in the host. A homologue of TGF- $\beta$ from B. malayi (BmTGH-2) shows a low level of binding ability with mammalian receptors [20]. A TGF- $\beta$ Mimic (TGM) of the murine parasitic nematode Heligmosomoides polygyrus was identified to act as a cytokine to exploit an endogenous pathway of immunoregulation in the host [57] and two other TGM members of $H$. polygyrus show an active function in an TGF- $\beta$ bioassay (cell line clone MFB-F11) that can induct $\mathrm{T}$ cell Foxp3 expression [58]. Therefore, the TGF- $\beta$ family of parasitic nematodes may take part in immunoregulation in their host.

In $H$. contortus adult females and males, $\mathrm{Hc}$-TGH-2 was also strongly expressed in the intestine, which is an important organ for the digestive system and a good source for mucosal candidate antigens to induce an immune response in the host $[59,60]$, suggesting that Hc-tgh-2 perhaps plays a role in digestion, absorption and host immune response. Furthermore, Hc-tgh-2 may also be involved in the reproductive development due to the strong expression in gonads (ovaries in adult females and testes in adult males) of $H$. contortus. In C. elegans, the daf-7 mutant worms showed an egg-laying defect and $C e-d a f-7$ is identified as a regulator that can expanse the larval germline progenitor pool $[7,18]$. Furthermore, phylogenetic analyses showed that $\mathrm{Hc}$-TGH-2 was close to Ce-DAF-7 of C. elegans, so we propose that $\mathrm{Hc}$-tgh-2 may regulate the germline proliferation and differentiation and the behavior of egg-laying in $H$. contortus. Another key molecule of the TGF- $\beta$ signalling pathway, $H c$-TGFBR2, also strongly expressed in the intestine and gonads of $H$. contortus adults [29], implying that the TGF- $\beta$ signalling pathway may play important roles in the digestive and reproductive systems in adults to facilitate the parasites survival and reproduction in the host. 


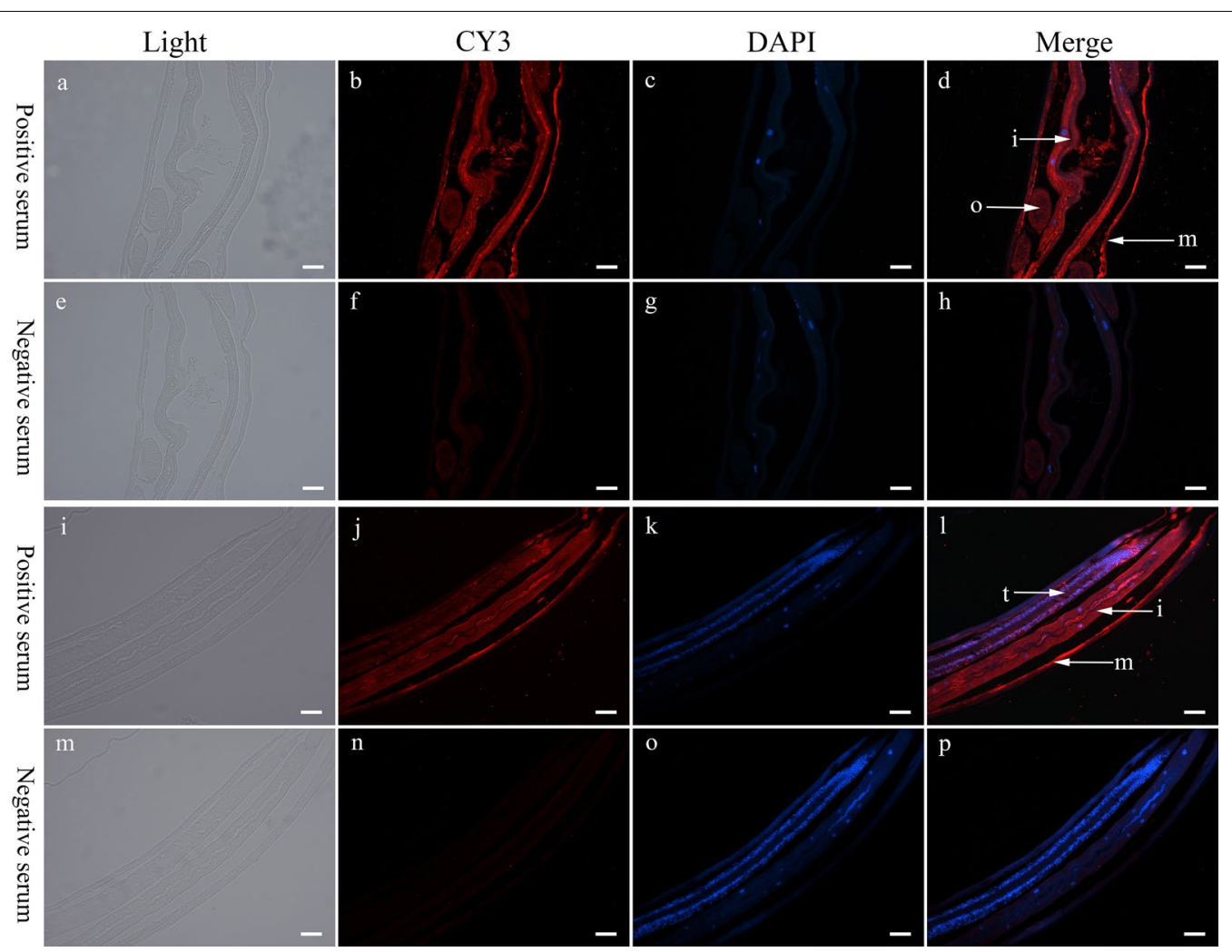

Fig. 3 The expression patterns of $\mathrm{HC}-\mathrm{TGH}-2$ in Haemonchus contortus adults. $\mathbf{a}-\mathbf{h}$, the expression pattern of $\mathrm{Hc}-\mathrm{TGH}-2$ in $\mathrm{H}$. contortus adult females with an exposure time of $2500 \mathrm{~ms}$. i-p the expression pattern of $\mathrm{Hc}-\mathrm{TGH}-2$ in $\mathrm{H}$. contortus adult males, with an exposure time of $3000 \mathrm{~ms}$. Positive serum was the serum from the final bleed after the last immunization (containing the antibody against recombinant $\mathrm{Hc}-\mathrm{TGH}-2$ ), negative serum is the serum from the pre-bleed before the first immunization (without the antibody of $\mathrm{Hc}-\mathrm{TGH}-2$ ). Abbreviations: i, intestine; $\mathrm{O}$, ovaries; $\mathrm{m}$, muscles of the body wall; t: testes. Scale-bars: $50 \mu \mathrm{m}$
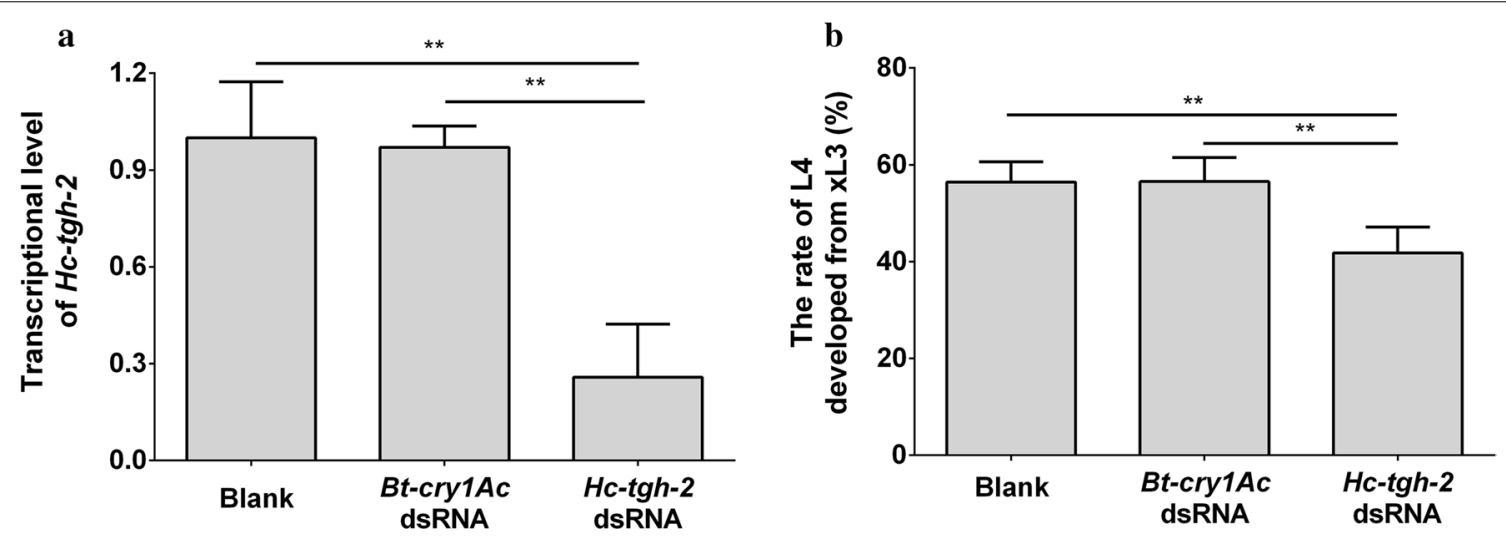

Fig. 4 Effect of Hc-tgh-2 dsRNA treatment on the XL3 development of Haemonchus contortus in vitro. a The transcriptional changes of Hc-tgh-2 in $\mathrm{H}$. contortus after RNAi detected by real-time PCR. $\mathbf{b}$ The ratios of $\mathrm{L} 4 \mathrm{~s}$ developed from $\times \mathrm{L} 3 \mathrm{~s}$ in vitro for another 7 days after RNAi. **P $<0.01$

\section{Conclusions}

In the present study, a daf-7-related TGF- $\beta$ ligand, $H c$ tgh-2, was characterized from the parasitic nematode H. contortus. Hc-tgh-2 was continuously transcribed in eight developmental stages of $H$. contortus with the highest level in iL3s, and the decreased transcription of Hc-tgh-2 in xL3s induced by the specific dsRNA could retard the development of xL3 to L4s in vitro, suggesting that Hc-tgh-2 could regulate the development from $\mathrm{xL} 3$ to L4 in $H$. contortus. The immunohistochemical 
results indicated that $\mathrm{Hc}$-TGH-2 was expressed in the muscle of the body wall, intestine and gonads of adult stages of $H$. contortus, suggesting that Hc-tgh-2 may play important roles in the digestive and reproductive systems in $H$. contortus adults. Taken together, TGF- $\beta$ $H c$-TGH-2 could play an important role in the transition from the free-living (L3s) to the parasitic stage (L4), digestion, absorption, host immune response and reproductive development in $H$. contortus.

\section{Supplementary information}

Supplementary information accompanies this paper at https://doi. org/10.1186/s13071-020-04196-x.

Additional file 1: Table S1. Oligonucleotide primers $\left(5^{\prime}-3^{\prime}\right)$ used in the present study.

Additional file 2: Figure S1. Prokaryotic expression and purification of $\mathrm{HC}-\mathrm{TGH}-2$, as analyzed by SDS-PAGE. Lane 1: protein marker; Lane 2: purified recombinant protein $\mathrm{HC}-\mathrm{TGH}-2$; Lane 3: recombinant protein expression non-induced by IPTG; Lane 4: recombinant protein $\mathrm{Hc}-\mathrm{TGH}-2$ expression induced by IPTG.

Additional file 3: Figure S2. Western blot analysis detecting the expression of native Hc-TGH-2 in Haemonchus contortus adult worms. The polyclonal antibody of recombinant $\mathrm{Hc}-\mathrm{TGH}-2$ protein were analyzed by western blot using the total protein of Haemonchus contortus adults. Lane 1: negative serum without the antibody against recombinant $\mathrm{Hc}-\mathrm{TGH}-2$; Lane 2: positive serum with the antibody against recombinant $\mathrm{Hc}-\mathrm{TGH}-2$.

\section{Abbreviations}

BSA: bovine serum albumin; DAPI: 4, 6-diamidino-2-phenylindole; dsRNA: double-stranded RNA; EBSS: Earle's Balanced Salt Solution; ML: maximum likelihood; MP: maximum parsimony; NJ: neighbour-joining; PBS: phosphate buffer solution; SDS-PAGE: sodium dodecyl sulfate polyacrylamide gel electrophoresis; ssRNA: single-stranded RNA.

\section{Acknowledgements}

Not applicable.

\section{Authors' contributions}

$\mathrm{MH}$ conceived the project. LH carried out laboratory work. LH, FFL and WWD performed the bioinformatics data analyses. HL, BYZ, CQW, CXZ, LL, TTL, TZ and RF managed sheep hosts and $\mathrm{H}$. contortus isolates. LH wrote the manuscript, $\mathrm{MH}$ reviewed the manuscript and contributed to the final submission. All authors read and approved the final manuscript.

\section{Funding}

This study was supported by the National Key Basic Research Program (973 program) of China (Grant no. 2015CB150300) and the National Natural Science Foundation of China (Grant no. 31872462) to $\mathrm{MH}$; and the Natural Science Foundation of Hubei Province (Grant No. 2017CFA020) to RF and MH.

\section{Availability of data and materials}

Data supporting the conclusions of this article are included within the article and its additional files.

\section{Ethics approval and consent to participate}

Helminth-free goats used for the production of $\mathrm{H}$. contortus were maintained in accordance with protocols approved by the Scientific Ethic Committee of Huazhong Agricultural University (Permit code: HZAUGO-2015-006) and Animal Ethics Guidelines from the People's Republic of China.

\section{Consent for publication}

Not applicable.

\section{Competing interests}

The authors declare that they have no competing interests.

Received: 20 February 2020 Accepted: 17 June 2020

Published online: 26 June 2020

\section{References}

1. Galat A. Common structural traits for cystine knot domain of the TGF beta superfamily of proteins and three-fingered ectodomain of their cellular receptors. Cell Mol Life Sci. 2011;68:3437-51.

2. Herpin A, Lelong C, Favrel P. Transforming growth factor-beta-related proteins: an ancestral and widespread superfamily of cytokines in metazoans. Dev Comp Immunol. 2004;28:461-85.

3. Chen W, Ten Dijke P. Immunoregulation by members of the TGF beta superfamily. Nat Rev Immunol. 2016;16:723-40.

4. Kashima R, Hata A. The role of TGF-beta superfamily signaling in neurological disorders. Acta Biochim Biophys Sinica. 2018;50:106-20.

5. Santibañez JF, Quintanilla M, Bernabeu C. TGF-beta/TGF-beta receptor system and its role in physiological and pathological conditions. Clin Sci (Lond). 2011;121:233-51.

6. Patterson GI, Padgett RW. TGF $\beta$-related pathways. Roles in Caenorhabditis elegans development. Trends Genet. 2000;16:27-33.

7. Gumienny TL, Savage-Dunn C. TGF- $\beta$ signaling in C. elegans. Wormbook. 2013;319:1.

8. Savage-Dunn C, Padgett RW. The TGF- $\beta$ family in Caenorhabditis elegans. Cold Spring Harb Perspect Biol. 2017;9:a022178.

9. Morita K, Chow KL, Ueno N. Regulation of body length and male tail ray pattern formation of Caenorhabditis elegans by a member of TGF-beta family. Development. 1999;126:1337-47.

10. Suzuki Y, Yandell MD, Roy PJ, Krishna S, Savage-Dunn C, Ross RM, et al. A BMP homolog acts as a dose-dependent regulator of body size and male tail patterning in Caenorhabditis elegans. Development. 1999;126:241-50.

11. Zhang $X$, Zhang Y. Neural-immune communication in Caenorhabditis elegans. Cell Host Microbe. 2009;5:425-9.

12. Roberts AF, Gumienny TL, Gleason RJ, Wang H, Padgett RW. Regulation of genes affecting body size and innate immunity by the DBL-1/BMP-like pathway in Caenorhabditis elegans. BMC Dev Biol. 2010;10:61.

13. So S, Tokumaru T, Miyahara K, Ohshima Y. Control of lifespan by food bacteria, nutrient limitation and pathogenicity of food in C. elegans. Mech Ageing Dev. 2011;132:210-2.

14. Ren P, Lim CS, Johnsen R, Albert PS, Pilgrim D, Riddle DL. Control of C. elegans larval development by neuronal expression of a TGF-beta homolog. Science. 1996;274:1389-91.

15. Schackwitz WS, Inoue T, Thomas JH. Chemosensory neurons function in parallel to mediate a pheromone response in C. elegans. Neuron. 1996;17:719-28.

16. Shaw WM, Luo S, Landis J, Ashraf J, Murphy CT. The C. elegans TGFbeta dauer pathway regulates longevity via insulin signaling. Curr Biol. 2007;17:1635-45.

17. Greer ER, Pérez CL, Gilst MRV, Lee BH, Ashrafi K. Neural and molecular dissection of a C. elegans sensory circuit that regulates fat and feeding. Cell Metab. 2008;8:118-31.

18. Dalfó D, Michaelson D, Hubbard EJ. Sensory regulation of the C. elegans germline through TGF-beta-dependent signaling in the niche. Curr Biol. 2012;22:712-9.

19. Gomez-Escobar N, Lewis E, Maizels RM. A novel member of the transforming growth factor-beta (TGF-beta) superfamily from the filarial nematodes Brugia malayi and B. pahangi. Exp Parasitol. 1998;88:200-9.

20. Gomez-Escobar N, Gregory WF, Maizels RM. Identification of tgh-2, a filarial nematode homolog of Caenorhabditis elegans daf-7 and human transforming growth factor beta, expressed in microfilarial and adult stages of Brugia malayi. Infect Immun. 2000;68:6402-10.

21. Brand AM, Varghese G, Majewski W, Hawdon JM. Identification of a DAF-7 ortholog from the hookworm Ancylostoma caninum. Int J Parasitol. 2005;35:1489-98.

22. Freitas TC, Arasu P. Cloning and characterisation of genes encoding two transforming growth factor-beta-like ligands from the hookworm, Ancylostoma caninum. Int J Parasitol. 2005;35:1477-87. 
23. Crook M, Thompson FJ, Grant WN, Viney ME. daf-7 and the development of Strongyloides ratti and Parastrongyloides trichosuri. Mol Biochem Parasitol. 2005;139:213-23.

24. Massey HC, Castelletto ML, Bhopale VM, Schad GA, Lok JB. Sst-tgh-1 from Strongyloides stercoralis encodes a proposed ortholog of daf-7 in Caenorhabditis elegans. Mol Biochem Parasitol. 2005;142:116-20.

25. Stoltzfus JD, Minot S, Berriman M, Nolan TJ, Lok JB. RNAseq analysis of the parasitic nematode Strongyloides stercoralis reveals divergent regulation of canonical dauer pathways. PLoS Negl Trop Dis. 2012;6:e1854.

26. Crook M, Grant K, Grant WN. Failure of Parastrongyloides trichosuri daf-7 to complement a Caenorhabditis elegans daf-7 (e1372) mutant: implications for the evolution of parasitism. Int J Parasitol. 2010;40:1675-83.

27. McSorley HJ, Grainger JR, Harcus Y, Murray J, Nisbet AJ, Knox DP, et al. daf7-related TGF-beta homologues from trichostrongyloid nematodes show contrasting life-cycle expression patterns. Parasitology. 2010;137:159-71.

28. He L, Gasser RB, Korhonen PK, Di W, Li F, Zhang H, et al. A TGF-beta type I receptor-like molecule with a key functional role in Haemonchus contortus development. Int J Parasitol. 2018;48:1023-33.

29. He L, Gasser RB, Li T, Di W, Li F, Zhang H, et al. A TGF-beta type II receptor that associates with developmental transition in Haemonchus contortus in vitro. PLoS Negl Trop Dis. 2019;13:e0007913.

30. Di W, Liu L, Zhang T, Li F, He L, Wang C, et al. A DAF-3 co-Smad molecule functions in Haemonchus contortus development. Parasit Vectors. 2019:12:609.

31. Zawadzki JL, Kotze AC, Fritz JA, Johnson NM, Hemsworth JE, Hines BM, et al. Silencing of essential genes by RNA interference in Haemonchus contortus. Parasitology. 2012;139:613-29.

32. Tamura K, Stecher G, Peterson D, Filipski A, Kumar S. MEGA6: molecular evolutionary genetics analysis version 6.0. Mol Biol Evol. 2013;30:2725-9.

33. Wang J, Czech B, Crunk A, Wallace A, Mitreva M, Hannon GJ, et al. Deep small RNA sequencing from the nematode Ascaris reveals conservation, functional diversification, and novel developmental profiles. Genome Res. 2011;21:1462-77.

34. Ghedin E, Wang S, Spiro D, Caler E, Zhao Q, Crabtree J, et al. Draft genome of the filarial nematode parasite Brugia malayi. Science. 2007;317:1756-60.

35. Stein LD, Bao Z, Blasiar D, Blumenthal T, Brent MR, Chen N, et al. The genome sequence of Caenorhabditis briggsae: a platform for comparative genomics. PLoS Biol. 2003;1:E45.

36. Gunther CV, Georgi LL, Riddle DL. A Caenorhabditis elegans type I TGF $\beta$ receptor can function in the absence of type II kinase to promote larval development. Development. 2000;127:3337-47.

37. Lowe TM, Eddy SR. tRNAscan-SE: a program for improved detection of transfer RNA genes in genomic sequence. Nucleic Acids Res. 1997;25:955-64

38. Biga PR, Roberts SB, Iliev DB, McCauley LA, Moon JS, Collodi P, et al. The isolation, characterization, and expression of a novel GDF11 gene and a second myostatin form in zebrafish, Danio rerio. Comp Biochem Physiol B Biochem Mol Biol. 2005;141:218-30.

39. Gamer LW, Wolfman NM, Celeste AJ, Hattersley G, Hewick R, Rosen V. A novel BMP expressed in developing mouse limb, spinal cord, and tail bud is a potent mesoderm inducer in Xenopus embryos. Dev Biol. 1999:208:222-32.

40. Nakashima M, Toyono T, Akamine A, Joyner A. Expression of growth/differentiation factor 11, a new member of the BMP/TGFbeta superfamily during mouse embryogenesis. Mech Dev. 1999;80:185-9.

41. Zhu XQ, Korhonen PK, Cai H, Young ND, Nejsum P, von Samson-Himmelstjerna G, et al. Genetic blueprint of the zoonotic pathogen Toxocara canis. Nat Commun. 2015;6:6145.

42. Korhonen PK, Pozio E, La Rosa G, Chang BC, Koehler AV, Hoberg EP, et al. Phylogenomic and biogeographic reconstruction of the Trichinella complex. Nat Commun. 2016;7:10513.

43. Guo $X$, Zhang H, Zheng X, Zhou Q, Yang Y, Chen $X$, et al. Structural and functional characterization of a novel gene, Hc-daf-22, from the strongylid nematode Haemonchus contortus. Parasit Vectors. 2016;9:422.

44. Pfaffl MW. A new mathematical model for relative quantification in realtime RT-PCR. Nucleic Acids Res. 2001;29:e45.

45. Wright K. Antibodies a Laboratory Manual by E Harlow and D Lane. Biochem Mol Biol Educ. 1989;17:220.

46. Sommerville RI. The development of Haemonchus contortus to the fourth stage in vitro. J Parasitol. 1966;52:127-36.
47. Mapes CJ. The development of Haemonchus contortus in vitro. Parasitology. 1969;59:215-31.

48. Kotze AC, Bagnall NH. RNA interference in Haemonchus contortus: suppression of beta-tubulin gene expression in L3, L4 and adult worms in vitro. Mol Biochem Parasitol. 2006;145:101-10.

49. Crook M. The dauer hypothesis and the evolution of parasitism: 20 years on and still going strong. Int J Parasitol. 2014;44:1-8.

50. Viney ME, Thompson FJ, Crook M. TGF-beta and the evolution of nematode parasitism. Int J Parasitol. 2005;35:1473-5.

51. Tissenbaum HA, Hawdon J, Perregaux M, Hotez P, Guarente L, Ruvkun G. A common muscarinic pathway for diapause recovery in the distantly related nematode species Caenorhabditis elegans and Ancylostoma caninum. Proc Natl Acad Sci USA. 2000;97:460-5.

52. Blaxter ML, De Ley P, Garey JR, Liu LX, Scheldeman P, Vierstraete A, et al. A molecular evolutionary framework for the phylum Nematoda. Nature. 1998:392:71-5

53. Hawdon JM, Volk SW, Rose R, Pritchard DI, Behnke JM, Schad GA. Observations on the feeding behaviour of parasitic third-stage hookworm larvae. Parasitology. 1993;106:163-9.

54. Gamble HR, Mansfield LS. Characterization of excretory-secretory products from larval stages of Haemonchus contortus cultured in vitro. Vet Parasitol. 1996;62:291-305.

55. Samarasinghe $B$, Knox DP, Britton $C$. Factors affecting susceptibility to RNA interference in Haemonchus contortus and in vivo silencing of an H11 aminopeptidase gene. Int J Parasitol. 2011;41:51-9.

56. Sood ML, Kalra S. Histochemical studies on the body wall of nematodes: Haemonchus contortus (Rud., 1803) and Xiphinema insigne Loos, 1949. Z Parasitenkd. 1977;51:265-73.

57. Johnston CJC, Smyth DJ, Kodali RB, White MPJ, Harcus Y, Filbey KJ, et al. A structurally distinct TGF-beta mimic from an intestinal helminth parasite potently induces regulatory T cells. Nat commun. 2017;8:1741.

58. Smyth DJ, Harcus Y, White MPJ, Gregory WF, Nahler J, Stephens I, et al. TGF-beta mimic proteins form an extended gene family in the murine parasite Heligmosomoides polygyrus. Int J Parasitol. 2018;48:379-85.

59. Jasmer DP, Lahmers KK, Brown WC. Haemonchus contortus intestine: a prominent source of mucosal antigens. Parasite Immunol. 2007;29:139-51.

60. Wang C, Li F, Zhang Z, Yang X, Ahmad AA, Li X, et al. Recent research progress in China on Haemonchus contortus. Front Microbiol. 2017:8:1509.

\section{Publisher's Note}

Springer Nature remains neutral with regard to jurisdictional claims in published maps and institutional affiliations.

Ready to submit your research? Choose BMC and benefit from

- fast, convenient online submission

- thorough peer review by experienced researchers in your field

- rapid publication on acceptance

- support for research data, including large and complex data types

- gold Open Access which fosters wider collaboration and increased citations

- maximum visibility for your research: over 100M website views per year

At BMC, research is always in progress.

Learn more biomedcentral.com/submissions 